\title{
Corrigendum: Synthesis of Optimal Trajectories with Functions Control at the Level of the Kinematic Drive Couplings
}

\author{
${ }^{1}$ Relly Victoria Virgil Petrescu, ${ }^{2}$ Raffaella Aversa, ${ }^{2}$ Antonio Apicella, ${ }^{3}$ Samuel Kozaitis, ${ }^{4}$ Taher Abu-Lebdeh \\ and ${ }^{1}$ Florian Ion Tiberiu Petrescu
}

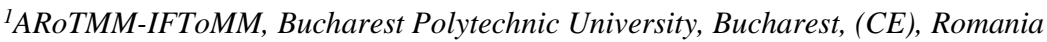

${ }^{2}$ Advanced Material Lab, Department of Architecture and Industrial Design,

Second University of Naples, 81031 Aversa (CE) Italy

${ }^{3}$ Florida Institute of Technology, USA

${ }^{4}$ North Carolina A and T State University, USA

Correction to: Journal of Mechatronics and Robotics

http://doi.org/10.3844/jmrsp.2017.66.74, published online 12 December 2017;

updated 29 April 2019

The original version of this Article contained Mr. MirMilad Mirsayar as a Co-

Author. Mr. Mirsayar has not contributed to the preparation and publication of this manuscript.

These errors have now been corrected in the HTML and PDF versions of the Article.

http://doi.org/10.3844/jmrsp.2017.66.74. 